\title{
Direct Torque Control of Induction Machine based on Intelligent Techniques
}

\author{
Soufien Gdaim \\ Laboratory of Electronics and \\ Microelectronics of the FSM. \\ National Engineering School of \\ Monastir, Avenue Ibn ElJazzar, \\ 5019 Monastir, Tunisia.
}

\author{
Abdellatif Mtibaa \\ Laboratory of Electronics and \\ Microelectronics of the FSM. \\ National Engineering School of \\ Monastir, Avenue Ibn ElJazzar, \\ 5019 Monastir, Tunisia.
}

\author{
Mohamed Faouzi Mimouni \\ Research Unit " Réseaux et \\ Machines Electriques". \\ National Engineering School of \\ Monastir, Avenue Ibn ElJazzar, \\ 5019 Monastir, Tunisia.
}

\begin{abstract}
Induction machine drive based on Direct Torque Control (DTC) allows high dynamic performance with very simple hysteresis control scheme. Conventional Direct Torque Control (CDTC) suffers from some drawbacks such as high current, flux and torque ripple, difficulties in torque as well as flux control at very low speed. In this paper, we propose two intelligent approaches to improve the direct torque control of induction machine; fuzzy logic control and artificial neural networks control. We carry out a detailed comparison study between direct torque fuzzy control (DTFC), direct torque neural networks control (DTNNC) and CDTC applied to switching select voltage vector. The theoretical foundation principle, the numerical simulation procedure and the performances of both methods are also presented.
\end{abstract}

\section{Keywords}

Direct torque control, fuzzy logic control, neural networks, induction motor.

\section{INTRODUCTION}

The induction machine is one of the most widely used machines in industrial applications due to its reliability, relatively low cost and modest maintenance requirement [1]. High performance electrical drives require decoupled torque and flux control. This control is offered in a dynamic fashion by the direct torque control. In DTC the torque and flux are directly controlled using the selection of the optimum voltage vector. The switching logic control facilitates the generation of the stator voltage space vector, with a suitable choice of the switching pattern of the inverter, on the basis of the knowledge of the sector and the amplitude of the stator flux and the torque [2]. The DTC scheme is characterized by its simple implementation and its fast dynamic response. Nevertheless, DTC presents some disadvantages such as high current, flux and torque ripple, difficulties in torque and flux control at very low speed, slow transient response to the step change in torque during start-up [1], [3] [4]. It is well established that these disadvantages are mainly due to the use of hysteresis torque and flux controllers [5]. For this reason, most of the methods used to overcome these disadvantages are based on replacing the hysteresis with the nonhysteresis-based controllers.

Since it was first introduced in 1986 [4], several studies have been proposed by researchers to overcome disadvantages of CDTC drive [6]-[11]. The study proposed in [6] uses multiple inverters in order to reduce the torque ripples, but the number of power devices is higher, which consequently increases costs. Another solution consists of using space vector modulation (SVM) instead of improving the DTC look-up table [8]-[10].
This solution needs however several motor parameters and increases the complexity of the DTC algorithm. Currently, several works use techniques from artificial intelligence (AI) like neural networks, fuzzy logic and genetic algorithms [1], [3], [5], [11]. Artificial neural networks (ANNs) are able to learn the mapping between system signals' input and output without knowing its exact mathematical model. Some approaches use neural networks for parameters identification and state estimation of electrical machine [12]. Others use neural networks to emulate the switching table [2], [11], [13], without being able to reduce the torque and flux ripples. Fuzzy control also allows controlling systems without knowing the plant mathematic model. It uses the intuition and experience of the designer to build its control rule base. There are many applications using fuzzy controllers for induction machine control. For instance, in [3] and [5], DTC rules have been replaced with fuzzy rules. Fuzzy logic controllers based on space vector modulation have proven to be effective for DTC [8].

In this paper, two strategies of direct torque control are proposed and compared with respect to the CDTC strategy: a direct torque fuzzy control and a direct torque neural networks control. DTC based on AI techniques are applied to overcome some disadvantages of CDTC such as minimizing the torque, current and flux ripple. We use fuzzy logic (DTFC) and neural networks (DTNNC) controllers in order to replace the switching table and the two hysteresis controllers. The paper is organized as follows. In section 2, a brief layout to the motor model is presented. Then, we give more details on DTC in section 3. In sections 4 and 5 we present and discuss the DTFC and DTNNC approaches respectively. In section 6 we carry out a comparative study between all three DTC strategies: CDTC, DTFC and DTNNC. In the final section, we conclude the paper and draw the outlines of the future work.

\section{MATHEMATICAL MODEL OF INDUCTION MOTOR}

When the motor operates in both steady and transient states, the standard induction motor equivalent model can be used to calculate machine variables such as stator current, rotor current, developed torque, etc. The induction motor can be modeled with stator current and flux in reference $(\alpha, \beta)$ as state variables expressed as follows:

$$
\frac{d}{d t} X=A X+B U
$$

Where

$$
X=\left[\begin{array}{llll}
i_{s \alpha} & i_{s \beta} & \varphi_{r \alpha} & \varphi_{r \beta}
\end{array}\right]^{T}, \quad U=\left[\begin{array}{ll}
V_{s \alpha} & V_{s \beta}
\end{array}\right]^{T},
$$




$$
\begin{gathered}
\gamma=\left[\frac{R_{s}}{\sigma L_{s}}+\frac{R_{r} M^{2}}{L_{r}^{2} \sigma L_{s}}\right] \\
A=\left[\begin{array}{cccc}
-\gamma & 0 & \frac{k}{T_{r}} & k \omega_{r} \\
0 & -\gamma & -k \omega_{r} & \frac{k}{T_{r}} \\
\frac{M}{T_{r}} & 0 & -\frac{k}{T_{r}} & -\omega_{r} \\
0 & \frac{M}{T_{r}} & \omega_{r} & -\frac{k}{T_{r}}
\end{array}\right], B=\frac{1}{\sigma L_{s}}\left[\begin{array}{cc}
1 & 0 \\
0 & 1 \\
0 & 0 \\
0 & 0
\end{array}\right]
\end{gathered}
$$

These differential equations are used for the simulations presented in this paper.

\section{PRINCIPLE OF THE DTC}

The diagram of CDTC for an induction motor drive is shown in Figure 1. $T_{e}{ }^{*}$ and $\varphi_{s}{ }^{*}$ are torque and flux reference values; $T_{e}$ and $\varphi_{s}$ are the estimated torque and stator flux values; $\omega^{*}$ is the command speed value; $\omega$ is the real speed value and $\theta_{s}$ is the stator flux angle.

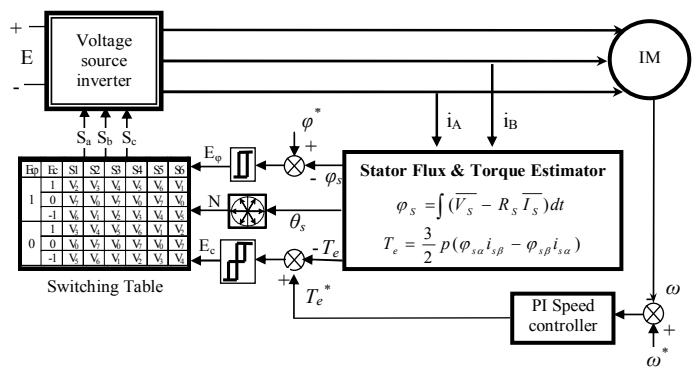

Figure 1. Diagram of the CDTC method

A PI or PID controller is used to determine the reference torque, based on the difference between the reference and the instantaneous speed of the motor.

The basic idea of the DTC concept is to choose the best vector of the voltage, which makes the flux rotate and produce the desired torque. During this rotation, the amplitude of the flux remains in a pre-defined band [14]. In order to control the induction motor, the supply voltage and stator current are sampled. Only two phase currents are needed to measure $i_{A}$ and $i_{B}$, the third phase can be calculed as follow: $i_{C}=-i_{A}-i_{B}$. The stator flux on the stationary reference axes $\alpha \beta$ is estimated as follows:

$$
\left\{\begin{array}{l}
\Phi_{s \alpha}=\int\left(V_{s \alpha}-R_{s} i_{s \alpha}\right) d t \\
\Phi_{s \beta}=\int\left(V_{s \beta}-R_{s} i_{s \beta}\right) d t
\end{array}\right.
$$

where $\Phi_{s}$ is the stator flux and $\mathrm{R}_{\mathrm{s}}$ is the stator resistance. The module of the stator flux is given by equation (3), the developed electromagnetic torque $T_{e}$ of the motor can be evaluated by equation (4) and the angle between the referential and $\varphi_{\mathrm{s}}$ is presented by equation (5).

$$
\phi_{s}=\sqrt{\varphi_{s \alpha}^{2}+\varphi_{s \beta}^{2}}
$$

$$
\begin{aligned}
& T_{e}=\frac{3}{2} p\left(i_{s \beta} \varphi_{s \alpha}-i_{s \alpha} \varphi_{s \beta}\right) \\
& \theta_{s}=\tan ^{-1}\left(\frac{\varphi_{s \alpha}}{\varphi_{s \beta}}\right)
\end{aligned}
$$

The estimated values of the torque and stator flux are compared to the command values, $T_{e}{ }^{*}$ and $\varphi_{s}{ }^{*}$ respectively. It can be seen from figure 1 that the error between the estimated torque $T_{e}$ and the reference torque $T_{e}{ }^{*}$ is the input of a three level hysteresis comparator, where the error between the estimated stator flux magnitude $\varphi_{s}$ and the reference stator flux magnitude $\varphi_{s}{ }^{*}$ is the input of a two level hysteresis comparator.

Finally, the outputs of the comparators with stator flux sector, where the stator flux space vector is located, select an appropriate inverter voltage vector from the switching Table 1 . The selected voltage vector will be applied to the induction motor at the end of the sample time [4].

Table 1. The switching table for basic DTC

\begin{tabular}{|c|c|c|c|c|c|c|c|}
\hline $\mathrm{E} \varphi$ & $\mathrm{Ec}$ & $\mathrm{S} 1$ & $\mathrm{~S} 2$ & $\mathrm{~S} 3$ & $\mathrm{~S} 4$ & $\mathrm{~S} 5$ & $\mathrm{~S} 6$ \\
\hline \multirow{4}{*}{1} & 1 & $\mathrm{~V}_{2}$ & $\mathrm{~V}_{3}$ & $\mathrm{~V}_{4}$ & $\mathrm{~V}_{5}$ & $\mathrm{~V}_{6}$ & $\mathrm{~V}_{1}$ \\
\cline { 2 - 8 } & 0 & $\mathrm{~V}_{7}$ & $\mathrm{~V}_{0}$ & $\mathrm{~V}_{7}$ & $\mathrm{~V}_{0}$ & $\mathrm{~V}_{7}$ & $\mathrm{~V}_{0}$ \\
\cline { 2 - 8 } & -1 & $\mathrm{~V}_{6}$ & $\mathrm{~V}_{1}$ & $\mathrm{~V}_{2}$ & $\mathrm{~V}_{3}$ & $\mathrm{~V}_{4}$ & $\mathrm{~V}_{5}$ \\
\hline \multirow{3}{*}{0} & 1 & $\mathrm{~V}_{3}$ & $\mathrm{~V}_{4}$ & $\mathrm{~V}_{5}$ & $\mathrm{~V}_{6}$ & $\mathrm{~V}_{1}$ & $\mathrm{~V}_{2}$ \\
\cline { 2 - 8 } & 0 & $\mathrm{~V}_{0}$ & $\mathrm{~V}_{7}$ & $\mathrm{~V}_{0}$ & $\mathrm{~V}_{7}$ & $\mathrm{~V}_{0}$ & $\mathrm{~V}_{7}$ \\
\cline { 2 - 8 } & -1 & $\mathrm{~V}_{5}$ & $\mathrm{~V}_{6}$ & $\mathrm{~V}_{1}$ & $\mathrm{~V}_{2}$ & $\mathrm{~V}_{3}$ & $\mathrm{~V}_{4}$ \\
\hline
\end{tabular}

Vectors $\mathrm{V}_{1}, \ldots, \mathrm{V}_{6}$ represent the six active vectors that can be generated by a voltage source inverter (VSI) where $\mathrm{V}_{0}$ and $\mathrm{V}_{7}$ are the two zero voltage vectors. Figure 2 gives the partition of the complex plan in six angular sectors $\mathrm{S}_{\mathrm{i}=1 \ldots 6}$.

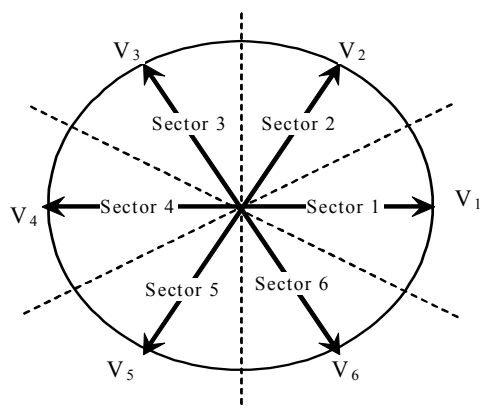

Figure 2. Partition of the complex plan in six angular sectors

When flux is in zone $i$, vector $V_{i+1}$ or $V_{i-1}$ is selected to increase the level of the flux, and $\mathrm{V}_{\mathrm{i}+2}$ or $\mathrm{V}_{\mathrm{i}-2}$ is selected to decrease it. At the same time, vector $V_{i+1}$ or $V_{i-2}$ is selected to increase the level of torque, and $\mathrm{V}_{\mathrm{i}-1}$ or $\mathrm{V}_{\mathrm{i}-2}$ is selected to decrease it.

If $\mathrm{V}_{0}$ or $\mathrm{V}_{7}$ is selected, the rotation of flux is stopped and the torque decreases whereas the amplitude of flux remains unchanged. This shows that the choice of the vector tension depends on the sign of the error of flux and torque independently from its amplitude [4]. This explains why the output of the hysteresis comparator of flux and torque must be a Boolean variable. We can add a band of hysteresis around zero to avoid useless commutations when the error of flux is very small [4]. 
With this type of hysteresis comparator, we can easily control and maintain the end of the vector flux within a circular ring.

\section{FUZZY LOGIC DTC CONTROLLER 4.1 Principles of Fuzzy Torque Control}

Since none of the inverter switching vectors is able to generate the exact voltage required to produce the desired changes in torque and flux, torque and flux ripples compose a real problem in DTC induction motor drive [15]. In this section, a fuzzy approach is proposed to reduce torque ripple. This target is achieved by the fuzzy controller which determinates the desired inverter vector state. Figure 3 illustrates the proposed fuzzy version of the DTC with induction motor.

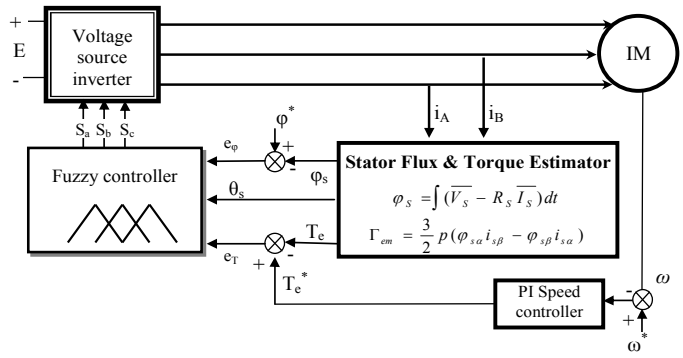

Figure 3. Diagram of the fuzzy logic DTC method

Our method of DTC differs from the conventional one by using a fuzzy controller instead of the hysteresis and switching tables. The fuzzy controller is designed in such a way that it requires three inputs and one single output. The inputs are the error of torque, the error in stator and the stator flux angle.

The fuzzy controller generally consists of three parts: fuzzification, fuzzy reasoning and defuzzification. The fuzzification is performed using a membership function. The performance of the fuzzy controller is based upon both the shape of the membership function and the fuzzy reasoning rules.

\subsection{Fuzzy Variables}

The flux error membership function is represented by three fuzzy sets as shown in Figure 4: a negative flux error (N), a zero flux error $(\mathrm{Z})$ and a positive flux error $(\mathrm{P})$.

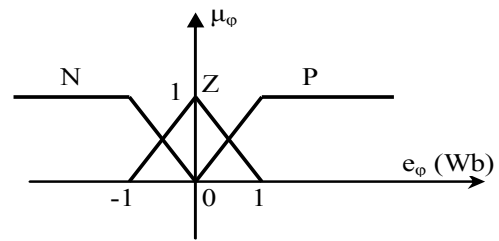

Figure 4. The fuzzy membership functions of $e_{\varphi}$.

The torque error membership function is decomposed into five fuzzy sets as shown in Figure 5: an entitled negative large error $(\mathrm{NL})$, a negative small error (NS), a zero error (Z), a positive small error (PS), and a positive large error (PL).

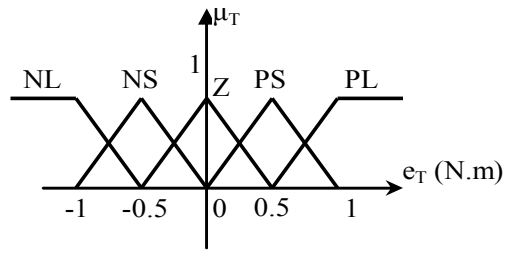

Figure 5. The fuzzy membership functions of $e_{T}$.
For more accuracy of stator flux angle $\theta_{\mathrm{s}}$, the universe of the discourse of this fuzzy variable is divided into twelve fuzzy sets denoted $\theta_{1}$ to $\theta_{12}$ as shown in Figure 6. The associated membership functions are defined in the same way as for flux and torque errors.

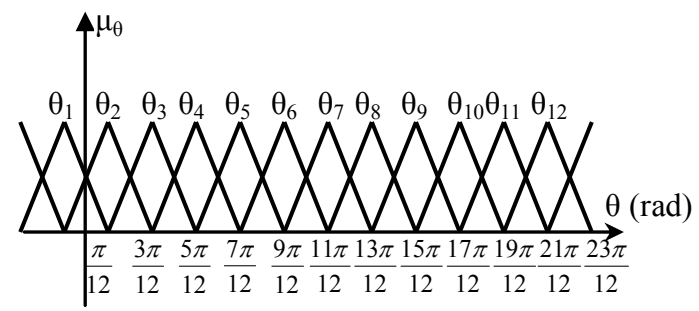

Figure 6. The fuzzy membership functions of $e_{\varphi}$.

This novel stator flux locus is introduced in Figure 7

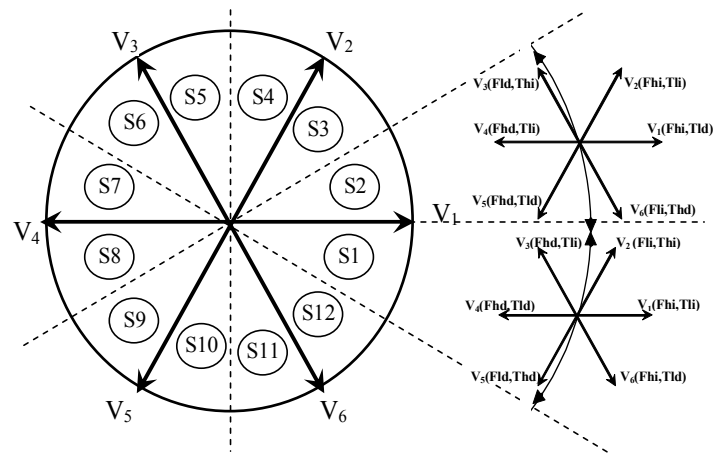

Figure 7. Stator flux vector with twelve sectors. Fhd/Fhi: flux high decrease /increase. Fsd/Fsi: flux small decrease /increase. Thd/Thi: Torque high decrease /increase. Tld/Tli: Torque low decrease /increase.

The output variable of the fuzzy controller is designed so that it has seven singleton subsets, one zero voltage vector and six non-zero voltage vectors. The membership functions of the output space voltage vectors are shown in Figure 8.

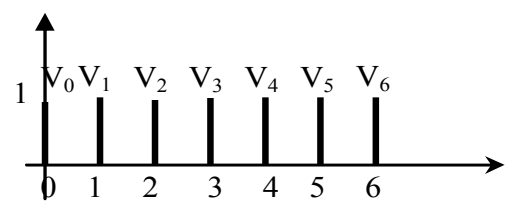

Figure 8. The fuzzy membership functions of output

\subsection{Fuzzy Control Rules}

The rule base monitors the behavior of the fuzzy controller. It stores the expert knowledge on how to control the plant. Fuzzy control rules can be deduced from the diagram of voltage vector in Figure 7. For example, supposing the positional angle $\theta$ of stator's flux is located in domain $\theta_{2}$, we can have the following decision rules: if desired control is to make torque decrease slowly and make flux increase rapidly, then desired decision is V1.

The control goal is to maintain the stator flux at a level value while keeping the torque's response fast. It is easy to show that we can build up to 180 control rules as shown in Table 2 . 
Table 2. Voltage vector fuzzy control table

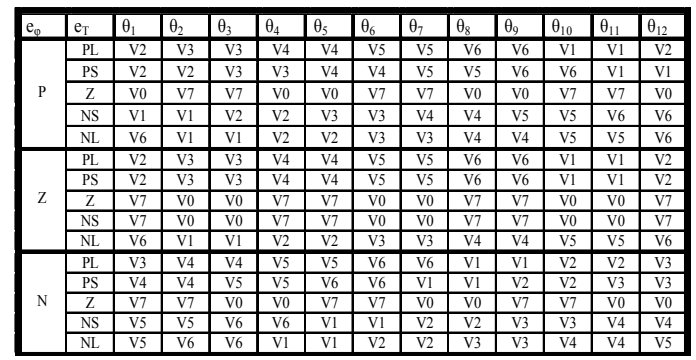

Each control rule from table 2 can be described using the input variables torque error $\mathrm{e}_{\mathrm{c}}$, flux error $\mathrm{e}_{\varphi}$, flux angle $\theta$ and the output variable $\mathrm{v}$ as shown in equation 6 :

$$
R_{i} \text { : if } e_{\varphi} \text { is } A_{i} \text { and } e_{T} \text { is } B_{i} \text { and } \theta \text { is } C_{i} \text { then } v \text { is } V_{i} \text {. }
$$

where $A_{i}, B_{i}$ and $C_{i}$ denote the fuzzy set of the variable $e_{\varphi}, e_{T}$ and $\theta$ respectively. $V_{i}$ and $R_{i}$ are the fuzzy singleton and control of rule number i.

\subsection{Fuzzy Inferences}

The inference method used in this paper is Mamdani's procedure based on min-max decision. The membership functions of variables $\mathrm{A}, \mathrm{B}, \mathrm{C}$ and $\mathrm{V}$ are given by $\mu_{\mathrm{A}}, \mu_{\mathrm{B}}, \mu_{\mathrm{C}}$ and $\mu_{V}$ respectively. The weighting factor $\alpha_{i}$ for the $i^{\text {th }}$ rule is computed using the min operator:

$$
\begin{aligned}
& \alpha_{\mathrm{i}}=\min \left(\mu_{\mathrm{Ai}}(\mathrm{e} \varphi), \mu_{\mathrm{Bi}}\left(\mathrm{e}_{\mathrm{T}}\right), \mu_{\mathrm{Ci}}(\theta)\right) . \\
& \mu_{\mathrm{Vi}_{\mathrm{i}}}^{\prime}(\mathrm{v})=\min \left(\alpha_{\mathrm{i}}, \mu_{\mathrm{V}_{\mathrm{i}}}(\mathrm{v})\right)
\end{aligned}
$$

In this case, the outputs are crisp values.

The maximum criterion method is used for defuzzification. By this method, the value of fuzzy output which has the maximum possibility distribution is used as the control output.

$$
\mathrm{M}_{\mathrm{Vout}}^{\prime}(\mathrm{v})=\max _{i=1}^{180}\left(\mu_{\mathrm{Vi}}^{\prime}(\mathrm{v})\right)
$$

The concrete reasoning of fuzzy logic system is shown in the flowchart of Figure 9. For each combination of inputs, usually more than one rule is validated. Each rule generates a significant control action depending on the input values of the variables. Then defuzzification is applied to generate the control output.

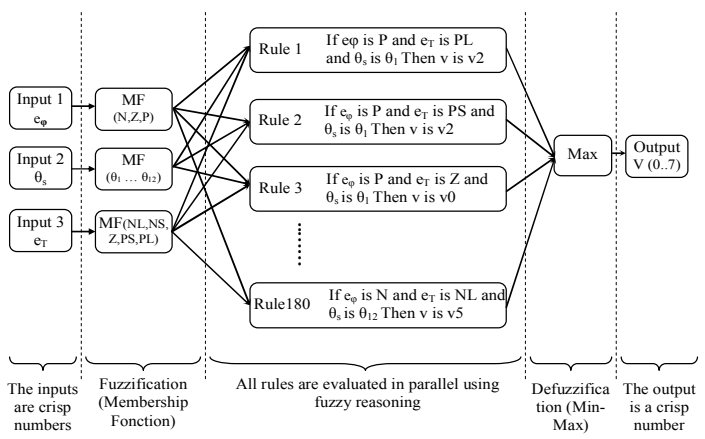

Figure 9. Flowchart of fuzzy logic system

\section{NEURAL NETWORKS DTC CONTROLLER}

\subsection{Principles of Artificial Neural Networks}

One of the most important features of Artificial Neural Networks (ANN) is their ability to learn and improve their operation using a training data [16]. The basic element of an ANN is the neuron which has a summer and an activation function as shown in Figure 10. The mathematical model of a neuron is given by:

$$
y=\varphi\left(\sum_{i=1}^{N} w_{i} * x_{i}+b\right)
$$

where $\left(\mathrm{x}_{1}, \mathrm{x}_{2} \ldots \mathrm{x}_{\mathrm{N}}\right)$ are the input signals of the neuron, $\left(\mathrm{w}_{1}\right.$, $\mathrm{w}_{2}, \ldots \mathrm{w}_{\mathrm{N}}$ ) are their corresponding weights and $\mathrm{b}$ a bias parameter. $\Phi$ is a tangent sigmoid function and $\mathrm{y}$ is the output signal of the neuron.

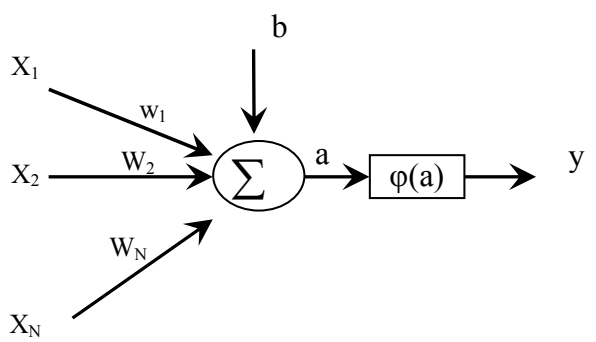

Figure 10. Representation of the artificial neuron

The ANN shown in Figure 11 can be trained by a learning algorithm which performs the adaptation of weights of the network iteratively until the error between target vectors and the output of the ANN is less than a predefined threshold [17]. Nevertheless, it is possible that the learning algorithm did not produce any acceptable solution for all input-output association problems. Anyway, results depend on several factors [16]-[18]:

- Network architecture (number of layers, number of neurons in each layer, etc.).

- Initial parameter values w (0).

- The details of the input-output mapping.

- Selected training data set (pairs of inputs and their corresponding desired outputs).

- The learning-rate constant.

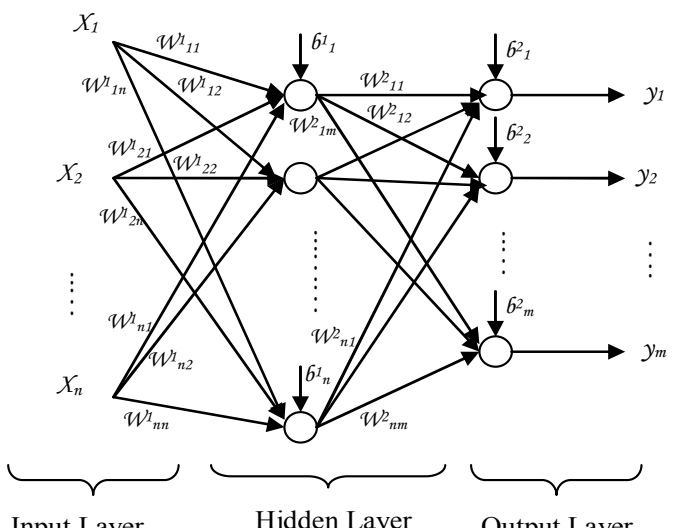

Input Layer
Output Layer

Figure 11. Structure of neural network 


\subsection{Learning Algorithms in Neural Networks}

The most popular supervised learning algorithm is backpropagation [16], which consists of a forward and backward action. In the forward step, the free parameters of the network are fixed, and the input signals are propagated throughout the network from the first layer to the last layer. In the forward phase, we compute a mean square error.

$$
E(k)=\frac{1}{N} \sum_{i=1}^{N}\left(d_{i}(k)-y_{i}(k)\right)^{2}
$$

where $d_{i}$ is the desired response, $y_{i}$ is the actual output produced by the network in response to the input $\mathrm{x}_{\mathrm{i}}, \mathrm{k}$ is the iteration number and $\mathrm{N}$ is the number of input-output training data.

The second step of the backward phase, the error signal $E(k)$ is propagated throughout the network of Figure 11 in the backward direction in order to perform adjustments upon the free parameters of the network in order to decrease the error $E(k)$ in a statistical sense [17]. The weights associated with the output layer of the network are therefore updated using the following formula [12]:

$$
w_{j i}(k+1)=w_{j i}(k)-\eta \frac{\partial E(k)}{\partial w_{j i}(k)}
$$

where $w_{j i}$ is the weight connecting the $j$ th neuron of the output layer to the $i$ th neuron of the previous layer, $\eta$ is the constant learning rate. Large values of $\eta$ may accelerate the ANN learning and consequently fasters convergence but may cause oscillations in the network output, whereas low values will cause slow convergence. Therefore, the value of $\eta$ has to be chosen carefully to avoid instability.

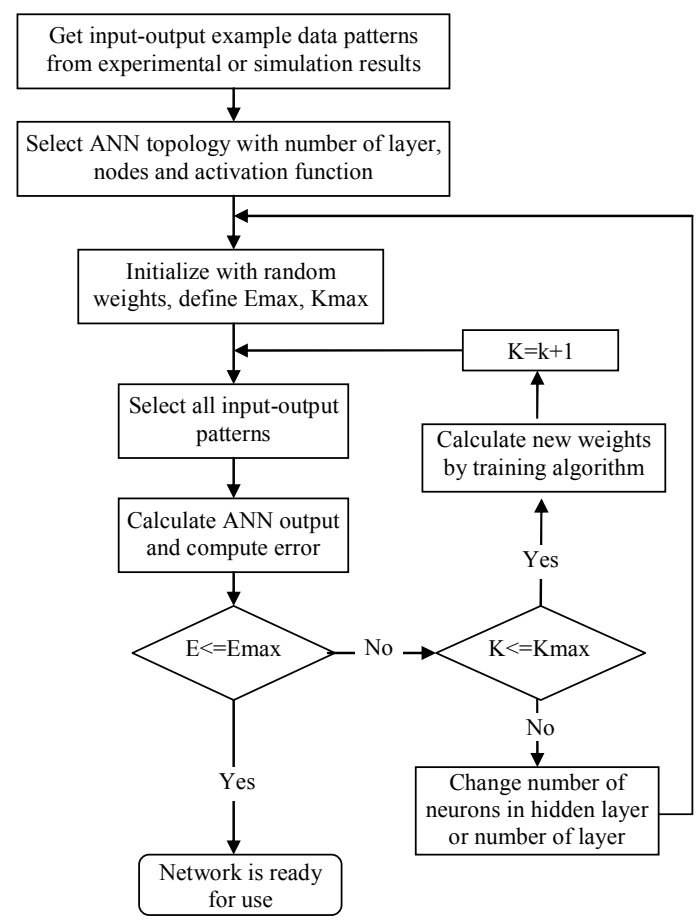

Figure12. Flowchart for training back propagation networks
To ensure fast convergence, we change the formula of equation (12) as shown in equation (13) where $\alpha$ is a positive constant called momentum constant.

$w_{j i}(k+1)=w_{j i}(k)-\eta \frac{\partial E(k)}{\partial w_{j i}(k)}+\alpha \Delta w_{j i}(k)$

The concrete back propagation training process is shown in the flowchart of Figure 12. Once the ANN is trained properly, it should be adequately tested using data which is different from the training set in order to test the validity of the model.

\subsection{ANN structure for DTC}

The basic structure of Direct Torque Neural Network Control (DTNNC) method for induction machine is presented in Figure 13. The artificial neural network replaces the switching table selector block and the two hysteresis controllers. After several tests, we choose an architecture 3-10-10-3, i.e. with two hidden layer, with a number of epochs of 3000 and an error of $10^{-3}$.

The ANN inputs are the error between the estimated flux value and its reference value, the difference between the estimated electromagnetic torque and the torque reference and the position of flux stator vector represented by the number of corresponding sector. The ANN output layer is composed of three neurons. Each neuron represents the state of one of the three pairs of the vector that will be applied to the induction motor. The rest of the whole system is the same like the classical structure of DTC presented in Figure 1.

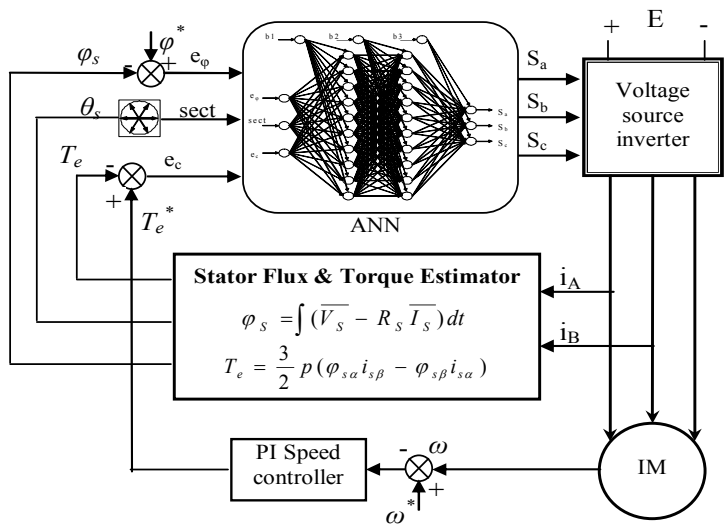

Figure 13. Structure of DTC using ANN strategy

\section{SIMULATION INTERPRETATION OF RESULTS}

AND

To test the performances of the fuzzy logic and neural networks control with direct torque control, the simulation of the system was conducted using the MATLAB tool. Motor's parameters for simulation are given in Table 3. Figures 14-17 show a comparison between the CDTC, DTFC and DTNNC.

The torque and flux references used in the simulation results of the Fuzzy direct torque control strategy are 10 N.m and 0.91 $w b$ respectively. The machine is running at $100 \mathrm{rad} / \mathrm{sec}$. The sampling period of the system is $50 \mu \mathrm{s}$. All four figures are the responses to step change torque command from zero to 10 N.M, which is applied at 0 sec.

The simulation results in Figure 14 ( $a, b$ and $c)$ show the response of electromagnetic torque of the CDTC, fuzzy DTC 
and neural network respectively. It can be seen that the torque's ripples with fuzzy direct torque control in steady state is significantly reduced compared to conventional and neural networks DTC. It is obvious from Figure 14.d that in fuzzy direct torque control, the torque trajectory is established quickly than in the conventional or the neural network DTC. The torque trajectories with conventional and neural networks DTC in startup are almost similar.

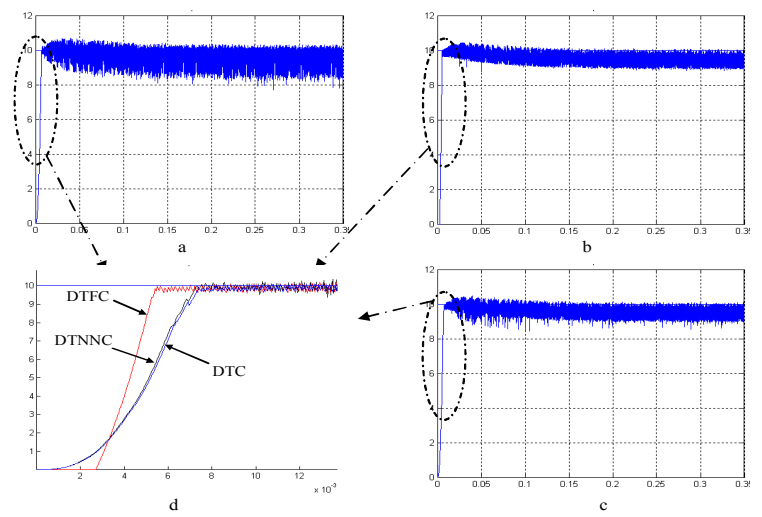

(a).CDTC. (b). DTFC. (c). DTNNC. (d) Conventional, Fuzzy and neural DTC plots

Figure 14. Electromagnetic torque response

Figure $15(\mathrm{a}, \mathrm{b}$ and $\mathrm{c})$ illustrates the response of stator flux magnitude of the CDTC, fuzzy DTC and neural network respectively. Compared with the CDTC, ripple of stator flux with fuzzy and neural network DTC is reduced significantly. The stator flux of the fuzzy DTC has the fast response time in transient state as shown in Figure 15.d.
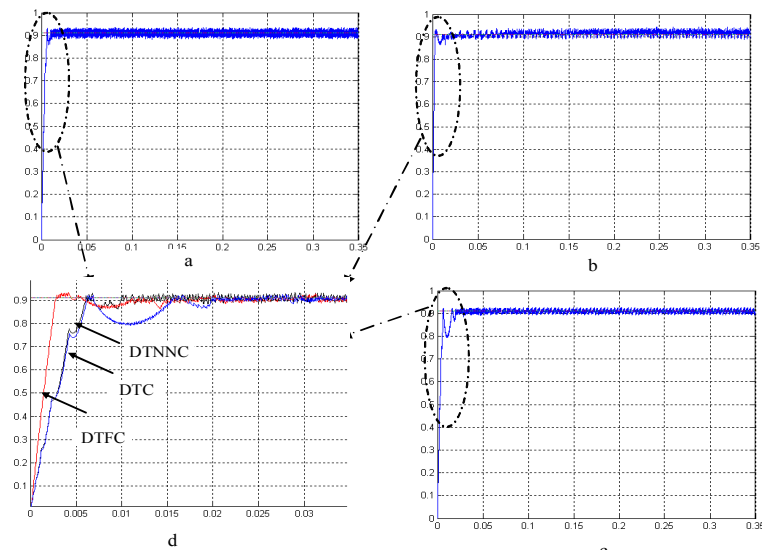

(a).CDTC. (b). DTFC. (c). DTNNC. (d) Conventional, Fuzzy and neural DTC

Figure 15. The stator flux magnitude

The simulation results in Figure16 (a, b and c) show that the current's stator ripples with direct torque neural networks control in steady state is significantly reduced compared to CDTC. Compared to the neural DTC, ripple of stator current with fuzzy DTC is almost similar.
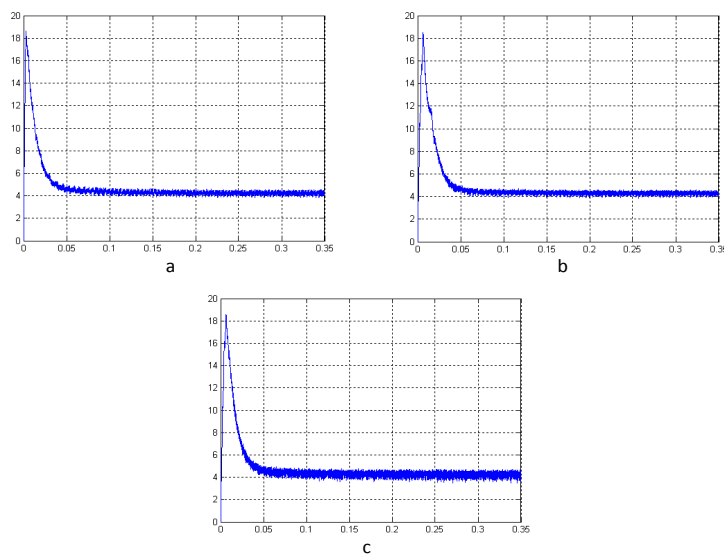

(a). Fuzzy DTC. (b).Neural network DTC. (c). CDTC.

Figure 16. The stator current magnitude

Figure 17 ( $\mathrm{a}, \mathrm{b}$ and $\mathrm{c})$ describes the stator flux vector trajectory which is almost circular. In this figure it can be noticed that fuzzy controller offers the fast transient responses and has better performance than the CDTC method. Compared to the CDTC, ripple of stator flux trajectory of neural network is significantly reduced.
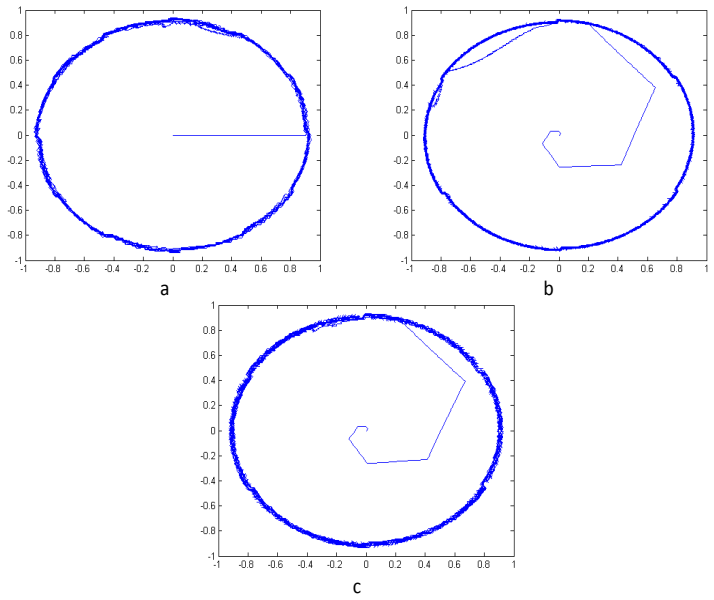

(a). Fuzzy DTC. (b). Neural network DTC. (c). CDTC.

\section{Figure 17. The stator flux vector trajectory}

In all the simulations presented here, we can easealy observe that our methods reaches better performances than the CDTC method with respect to reducing the torque, flux and current ripple and maintaining a good torque response.

Table 3. Induction Motor parameters

\begin{tabular}{|l|c|}
\hline \multicolumn{1}{|c|}{ Voltage } & $220 / 380 \mathrm{v}$ \\
\hline Pair pole & 2 \\
\hline Stator resistance $\mathrm{Rs}$ & $5.717 \Omega$ \\
\hline Rotor resistance $\mathrm{Rr}$ & $4.282 \Omega$ \\
\hline Stator inductance $\mathrm{Ls}$ & $0.464 \mathrm{H}$ \\
\hline Rotor inductance $\mathrm{Lr}$ & $0.464 \mathrm{H}$ \\
\hline Mutual inductance M & $0.441 \mathrm{H}$ \\
\hline Moment of inertia J & $0.0049 \mathrm{Kg} . \mathrm{m}^{2}$ \\
\hline
\end{tabular}

\section{CONCLUSION AND FUTURE WORK}

In this paper, an improvement for direct torque control algorithm of induction machine is proposed using two intelligent approaches which consists of replacing the switching table 
selector block and the two hysteresis controllers. Simulations have shown that the two proposed strategies have better performances than the CDTC. In fact, they alloaw a significant reduced torque and stator flux ripples and a good starting behavior. Using the intelligent techniques, the selection of the voltage vector becomes much convenient and the switching state can be obtained when the error of the torque and stator flux is attained. The validity of the proposed control is confirmed by the simulative results. None of the known advantages of the CDTC are impacted by the proposed methods. It has been found that the direct torque fuzzy control strategy allows a higher dynamic behavior than the conventional and neural network DTC.

In the future research, the simulative results will be brought into the experimental system to prove the proposed neural network and fuzzy logic control. A digital implementation of these intelligent controls may be performed using different devices such as custom design, programmable logic, etc. In a Field Programmable Gate Array (FPGA), which is a family of programmable devices, multiple operations can be executed in parallel so that algorithms can run faster, which is required for control systems.

\section{REFERENCES}

1. Abbou A, Mahmoudi H. Performance of a sensorless speed control for induction motor using DTFC strategy and intelligent techniques. Journal of Electrical Systems. Volume 5, Issue 3, September 2009.

2. A. Sivasubramanian, B. Jayanand. Application of Neural Network Structure in Voltage Vector Selection of Direct Torque Control Induction Motor. International Journal of Applied Engineering Research. Volume 4 Number 6, 2009.

3. Luis R, Antoni A, Emiliano A, Marcel G. Novel Direct Torque Control (DTC) Sheme With Fuzzy Adaptive Torque- Ripple Reduction. IEEE Transactions On Industrial Electronics, vol 50, No.3, June 2003.

4. Takahashi I, Noguchi T. A new quick-response and high efficiency control strategy of an induction motor, IEEE trans. Vol IA-22, no 5. 1986.

5. Deng J, Tu L. Improvement of Direct Torque Control Lowspeed Performance by Using Fuzzy Logic Technique. International Conference on Mechatronics and Automation. June 25-28, Luoyang, china.

6. Toh C, Idris N, Yatim A, Muhamad N, Elbuluk M. Implementation of a New Torque and Flux Controllers for Direct Torque Control (DTC) of Induction Machine Utilizing Digital Signal Processor (DSP) and Field Programmable Gate Arrays (FPGA). Power Electronics Specialists Conference, 2005. IEEE 36th 16-16 June 2005.

7. Bibhu P, Dinkar P, Sabyasachi S. A Simple hardware realization of switching table based direct torque control of induction motor. Electric Power Systems research 2007. Elsevier Publisher.

8. Mengjia J, Jianqi Q, Cenwei S, Ruiguang L. A fuzzy DTC method with a SVM defuzzification to Permanent Magnet synchronous Machine. The 30th annual conference of the IEEE inductrial electronics society, November 2-5, 2004 korea.

9. Saurabh N, Pandya A, Chatterjee J. Torque Ripple Minimisation in direct torque control based IM drive, Part 1 : Single-rate control strategy. 978-1-4244-1762-9/08. 2008 IEEE.

10. Yuttana K, Suuttichai P, Hamid A. Modified Direct Torque Control method for induction motor drives based on amplitude and angle control of stator flux. Electric Power Systems research 2008. Elsevier Publisher.

11. Rajesh K, Gupta R, Bhangale S, Himanshu G. Artificial Neural Network Based Direct Torque Control of Induction Motor Drives. IET-UK International Conference on Information and Communication Technology in Electrical sciences (ICTES 2007)

12. A. Goedtel, I.. N. Silva, P. J. Serni, Load torque identification in induction motor using neural networks technique, Electric Power Syustem Research, Science Direct 2006.

13. A. Abbou, H. Mahmoudi. Performance of a sensorless speed control for induction motor using DTFC strategy and intelligent techniques. Journal of Electrical Systems. Volume 5, Issue 3, September 2009.

14. Kaboli S, Zlghadri M, Emadi A. A Fast Flux Search Controller for DTC Based Induction Motor Drives. Power Electronics Specialists Conference, 2005. PESC '05. IEEE 36th Publication Date: 16-16 June 2005.

15. Fatiha Z, Rachid N. Direct torque control of induction motor with fuzzy minimization torque ripple. Journal of electrique engineering, vol 56, no 7-8, 2005.

16. M. Cirstea, A. Dinu, J. Khor, M. Mccormick, "Neural and Fuzzy Logic Control of Drives and Power Systems", Newnes, An imprint of Elsevier Science First published 2002. 412 pages.

17. S. Haykin, "Neural Network - A comprehensive Foundation", Prentice Hall 1999. 897 pages.

18. B. Bose, "Power Electronics and Motor Drives, Advances and Trends", Academic Press is an imprint of Elsevier, published 2006, 935 pages. 